\title{
CIENCIAMATRIA
}

Revista Interdisciplinaria de Humanidades, Educación, Ciencia y Tecnología

Año VII. Vol. VII. N¹2. Enero - Junio. 2021

Hecho el depósito de ley: pp201602FA4721

ISSN-L: 2542-3029; ISSN: 2610-802X

Universidad Nacional Experimental Francisco de Miranda (UNEFM). Santa Ana de Coro. Venezuela

María-del-Carmen Sagbay-Llivichuzhca; Katina Vanessa Bermeo-Pazmiño;

Juan Diego Ochoa-Crespo

DOI $10.35381 / \mathrm{cm} . v 7 \mathrm{i} 12.430$

\section{Determinación del nivel de satisfacción de los consumidores en los supermercados del Cantón Sígsig}

\section{Determination of the level of consumer satisfaction in the supermarkets of Cantón Sígsig}

\author{
María-del-Carmen Sagbay-Llivichuzhca \\ maria.sagbay@est.ucacue.edu.ec \\ Universidad Católica de Cuenca, Cuenca \\ Ecuador \\ https://orcid.org/0000-0003-3996-9727 \\ Katina Vanessa Bermeo-Pazmiño \\ kbermeo@ucacue.edu.ec \\ Universidad Católica de Cuenca, Cuenca \\ Ecuador \\ https://orcid.org/0000-0002-4438-7855 \\ Juan Diego Ochoa-Crespo \\ jdochoac@ucacue.edu.ec \\ Universidad Católica de Cuenca, Cuenca \\ Ecuador \\ https://orcid.org/0000-0003-0781-2020
}

Recibido: 01 de octubre de 2020

Aprobado: 15 de diciembre de 2020 


\author{
CIENCIAMATRIA \\ Revista Interdisciplinaria de Humanidades, Educación, Ciencia y Tecnología \\ Año VII. Vol. VII. N¹2. Enero - Junio. 2021 \\ Hecho el depósito de ley: pp201602FA4721 \\ ISSN-L: 2542-3029; ISSN: 2610-802X \\ Universidad Nacional Experimental Francisco de Miranda (UNEFM). Santa Ana de Coro. Venezuela \\ María-del-Carmen Sagbay-Llivichuzhca; Katina Vanessa Bermeo-Pazmiño; \\ Juan Diego Ochoa-Crespo
}

\begin{abstract}
RESUMEN
El objetivo es analizar el nivel de satisfacción del consumidor en el servicio por parte de los supermercados del Cantón Sígsig, así como definir los factores de mejora para dichos supermercados. Metodológicamente de tipo descriptiva con diseño no experimental de campo. De la información obtenida de los clientes se pudo analizar que la mayoría de los clientes utilizan el internet como medio de información, pero los supermercados no realizan publicidad constante en las redes sociales y otros supermercados que no realizan ningún tipo de publicidad, los supermercados deben utilizar esto medios tecnológicos como una estrategia de marketing para captar nuevos clientes y difundir información sobre los productos que ofrecen. Los supermercados deben emplear programas de innovación o mejora continua en los establecimientos, en la encuesta realizada a los clientes se constató que los clientes buscan la comodidad para realizar sus transacciones y que el lugar sea amplio.
\end{abstract}

Descriptores: Estudio de mercado; consumidor; comercio interno. (Palabras tomadas del Tesauro UNESCO).

\begin{abstract}
Customer satisfaction is given by customer expectations and perceptions, recommendations and by the experiences they have had. The objective of this research is to determine the level of consumer satisfaction and to define the factors of improvement for these supermarkets in Canton Sígsig. The research was mixed, descriptive and explanatory. The methods applied in the research were with inductive-deductive approach that facilitated the management of information, as well as analytical-synthetic, historicallogical and systemic. It was evident that the supermarkets do not focus on good customer service, do not have staff with experience in collections and this generates discomfort to customers because of waiting time. It is recommended to implement a model of improvement in customer service and a mailbox for complaints and suggestions that will aim to improve the factors that influence customer satisfaction.
\end{abstract}

Descriptors: Market research; consumers; domestic trade. (Words taken from the UNESCO Thesaurus). 


\section{CIENCIAMATRIA}

Revista Interdisciplinaria de Humanidades, Educación, Ciencia y Tecnología

Año VII. Vol. VII. N¹2. Enero - Junio. 2021

Hecho el depósito de ley: pp201602FA4721

ISSN-L: 2542-3029; ISSN: 2610-802X

Universidad Nacional Experimental Francisco de Miranda (UNEFM). Santa Ana de Coro. Venezuela

María-del-Carmen Sagbay-Llivichuzhca; Katina Vanessa Bermeo-Pazmiño;

Juan Diego Ochoa-Crespo

\section{INTRODUCCIÓN}

Las empresas para poder permanecer en el mercado en la actualidad deben enfocarse en la satisfacción del cliente, ya que la satisfacción es un punto muy importante para que las empresas puedan mantenerse en el mercado y lograr cumplir los objetivos planteados. En este mundo globalizado las empresas deben saber que el cliente es el éxito de los negocios, porque si la empresa logra satisfacer las necesidades del cliente, las empresas obtendrán mayor rentabilidad.

La satisfacción del cliente es un componente fundamental por que engloba la percepción del cliente y refleja la opinión de los demás usuarios, las experiencias, el estado de ánimo, estos son aspectos relevantes para adquirir un producto o servicio (Mora-Contreras, 2011). Las empresas deben tener su visión de hacer clientes antes de las ventas porque hoy en día es más importante mantener un cliente que cerrar una venta. Los supermercados al ser empresas que constantemente venden productos masivos, contribuyen a crear valor para el cliente al permitir que el consumidor satisfaga sus necesidades, en la actualidad existe una gran variedad de negocios como supermercados, locales y kioscos.

Las empresas deben estar al tanto de los clientes, ya que estos son cada vez más exigentes, ya no solo buscan precio y calidad, sino también, una buena atención, servicio personalizado, comodidad, un ambiente agradable, sus expectativas y necesidades cambian en cada momento, en ese momento es donde las empresas ya deben tener un estudio previo de cómo conseguir que ese cliente pueda satisfacer su necesidad de manera exitosa (López, 2013).

Es fundamental conocer cuáles son los principales factores en los que se incurre en el proceso de compra y, a su vez, cuál es la mejor forma de hacerlo desde la parte administrativa hasta el cliente. Los factores que inciden en la actividad empresarial al momento de la compra son los precios competitivos, la calidad de la mercadería, el servicio al cliente, la distribución de la mercadería y el establecimiento. Si bien es cierto 
que el precio es un factor principal para atraer un nuevo cliente al momento de la decisión de la compra de un producto, los supermercados deben abordar estrategias con el fin cumplir con las expectativas de los clientes, pero este no es el único componente que se incluye en la decisión de compra, hay que tener en cuenta que tanto la calidad como la variedad constituyen también los elementos esenciales que satisfacen las necesidades de los clientes.

La atención al cliente hace que mismos sean leales con los proveedores y los mismos muestran estar dispuestos a repetir la compra, es decir, un cliente satisfecho contribuye con la empresa utilizando el marketing de boca a boca, las personas cuentan sus experiencias a otras personas, el cual recomienda a diferentes usuarios acudir a ese supermercado (Guadarrama-Tavira \& Rosales-Estrada, 2015).

Es importante que los propietarios o administradores de los negocios entiendan que es imprescindible brindar un servicio excelente, para que el usuario que adquiera el producto o servicio regrese de manera constante al mismo lugar, es importante hacer un énfasis en la atención personalizada, amabilidad, la cortesía, paciencia y un servicio adecuado para lograr satisfacer las necesidades del cliente y de manera evadir que el cliente tenga que acudir a la competencia a satisfacer sus necesidades (Rodríguez, et al., 2019).

Las organizaciones deben saber medir la satisfacción del cliente utilizando el método de medición de satisfacción directa e indirecta, en método directa generalmente se utilizan los cuestionarios, con el fin de saber cuál es la percepción del cliente. En el método indirecta las empresas pueden hacer, un buzón de quejas y reclamos, los sondeos tradicionales que pueden realizar a los empleados o los clientes, con el fin de obtener información relevante para cambiar los factores que estén influyen en la satisfacción del cliente (González, 2014).

Los consumidores actualmente no están satisfechos con el servicio que reciben de los supermercados ubicados en el Cantón Sígsig y a su vez existe el desconocimiento por parte de los dueños de los supermercados de los factores que deciden en la elección de 
CIENCIAMATRIA

Revista Interdisciplinaria de Humanidades, Educación, Ciencia y Tecnología

Año VII. Vol. VII. N¹2. Enero - Junio. 2021

Hecho el depósito de ley: pp201602FA4721

ISSN-L: 2542-3029; ISSN: 2610-802X

Universidad Nacional Experimental Francisco de Miranda (UNEFM). Santa Ana de Coro. Venezuela

María-del-Carmen Sagbay-Llivichuzhca; Katina Vanessa Bermeo-Pazmiño;

Juan Diego Ochoa-Crespo

la compra, y esto hace que los supermercados se estén volviendo insostenibles en el mercado.

El objetivo es analizar el nivel de satisfacción del consumidor en el servicio por parte de los supermercados del Cantón Sígsig, así como definir los factores de mejora para dichos supermercados.

\section{Referencial teórico}

\section{Satisfacción de los clientes, expectativas, percepción y beneficios}

La satisfacción al cliente desde hace mucho tiempo viene siendo una lucha que las empresas deben enfrentar de manera constante para permanecer en el mercado ya que los clientes son núcleo principal de las empresas. Las empresas deben estar a la par de los clientes, logrando cubrir las necesidades y expectativas de los mismos.

Según Kotler \& Armstrong (2007). Define la satisfacción al cliente como "El nivel del estado de ánimo de una persona que resulta de comparar el rendimiento percibido de un producto o servicio con sus expectativas" (p. 52). Según la definición antes mencionada la satisfacción del cliente este comprendido por tres elementos:

1.- El rendimiento percibido: es aquel beneficio que el cliente ha conseguido después de adquirir un producto o servicio.

2.- Las expectativas: son aquellas donde los clientes tienen las esperanzas de conseguir algo.

3.- Los niveles de satisfacción: los clientes una vez realizado las compras experimentan uno de estos tres niveles de: insatisfacción, satisfacción o complacencia.

La satisfacción al cliente está dada por las expectativas y las percepciones de los clientes, las recomendaciones por el servicio brindado o por el producto adquirido, por los resultados obtenidos, por las experiencias experimentadas o por las empresas de la competencia. Es imprescindible satisfacer cada una de las necesidades de los clientes, aunque estos sean cada vez más estrictos con sus requerimientos, es decir, el factor 


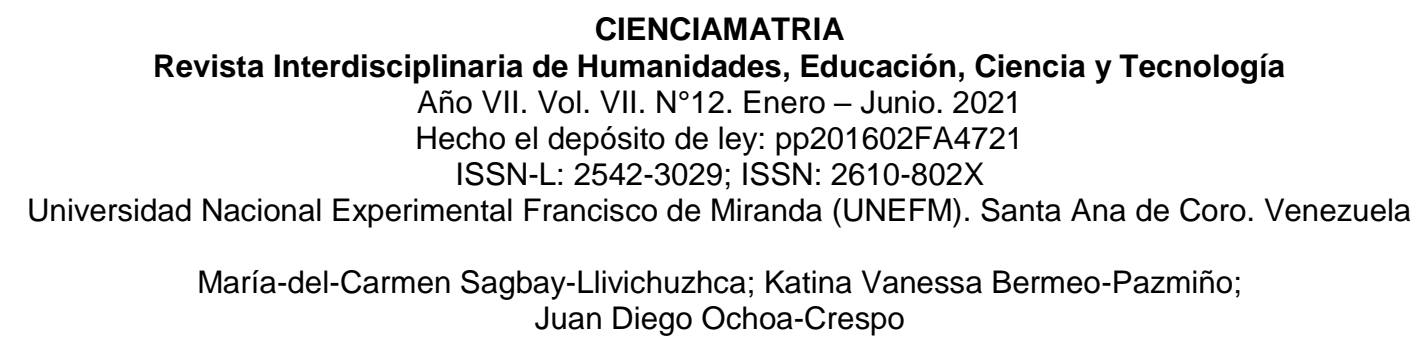

principal de una empresa es el cliente el cual forma parte fundamental de las mismas, en la actualidad los deseos de los clientes también incidencia en la satisfacción (MendozaNovillo, et al., 2019).

Hoy en día las personas emprenden varios negocios, con el fin de ir creciendo poco a poco en el mercado, el desconocimiento de información hace que le negocio no avance como lo planificado, el hecho de no atender bien al cliente perjudica drásticamente a la empresa por que el cliente es el factor que contribuye a que el negocio crezca y si no hay clientes no puede continuar funcionando el negocio, las personas antes de lanzarse al mundo de los negocios deben conocer todos esos aspectos, preguntar a personas expertas en negocios para que sean capacitados antes de emprender.

La satisfacción del cliente se encuentra relacionado con el conjunto de emociones ya sean estas positivas o negativas que se producen en el cliente o usuario al momento de comparar, el precio que ha tenido que pagar por adquirir un producto, un bien o servicio con relación a las expectativas que se tienen al momento de la adquisición, es decir si las emociones son positivas el cliente se sentirá satisfecho por ende es un cliente leal y también recomendara a otros clientes, mientas si los sentimientos son negativos, es decir al cliente o usuario están insatisfechos no regresaran a la empresa, y esto a su vez será una mala publicidad para las empresas (Bernal, et al., 2020).

Las expectativas son las esperanzas de hacer o conseguir algo, siendo esto la entrega de un producto o servicio, las mismas son creadas por la información de otros clientes, el nivel de expectativa varía con rapidez según las respuestas de los otros usuarios (Matsumoto-Nishizawa, 2014). Hay factores que inciden en las expectativas de los clientes, tanto en términos de prioridad de los criterios relacionados, cada criterio tiene relación con el nivel de expectativa.

Los factores como las necesidades o requisitos de los clientes dependen exclusivamente de los proveedores, el desempeño de los proveedores es un factor que afecta las expectativas de los clientes. Un proveedor que cumplió de manera satisfactoria lo 
solicitado por el cliente, contribuye que el mismo regrese de nuevo, y también existen proveedores que afectaron la expectativa de los clientes y los mismos buscan a otros proveedores, se debe tener en cuenta que los clientes esperan que el proveedor pueda satisfacer dichas necesidades (Bowersox, et al., 2007).

El éxito de una organización depende de la satisfacción de las necesidades y expectativas actuales y futuras de sus clientes. Las necesidades suelen ser objetivas y en la mayoría de los casos se definen en los propios documentos del cliente en forma de una orden de contrato de especificación de compra o por referencia a un estándar de la organización que las suministra (Cervera, 2002).

El nivel de satisfacción depende de la diferencia entre el valor percibido y las expectativas creadas con respecto al producto, y dependiendo de la implicación de la satisfacción que se ha logrado a largo plazo, podemos hablar de un aumento o disminución en el porcentaje de clientes perdidos, ocasionales o fieles. Las empresas deben intentar conseguir la mayor cantidad posible de clientes leales.

El rendimiento percibido del cliente se refiere a la valoración que hace un cliente del producto o servicio adquirido, y a su vez da su punto de vista de la experiencia percibida después de hacer las compras, la percepción puede varias de acuerdo a las experiencias propias de cada cliente según el transcurso del tiempo. Si el rendimiento percibido del producto no cumple con las expectativas del cliente, el cliente quedará insatisfecho, en este sentido tenemos la oportunidad de rectificar. Si el desempeño percibido del producto y las expectativas son las mismas, el cliente quedará satisfecho y podremos probar mejor el producto.

Finalmente, si el desempeño percibido es superior a las expectativas, el cliente quedará muy satisfecho y debemos aprovechar el desafío de mantener esta satisfacción (Pujadas, 2007). Según el nivel de satisfacción de un cliente, las organizaciones conocerán la lealtad del cliente, un cliente insatisfecho cambiara de proveedor de forma inmediata y 
un cliente satisfecho comunica a otros sus experiencias positivas sobre el producto. Existen algunas ventajas si las empresas logran la satisfacción de los clientes:

1. Un cliente satisfecho adquiere los productos toda la vida en un mismo establecimiento.

2. Un cliente está contento con su marca comenta a sus familiares o amigos sobre el producto o servicio.

3. Si cumples con sus expectativas, los clientes quedarán satisfechos y serán leales con la empresa, y no tendrá necesidad de acudir a la competencia.

El cliente es una persona que adquiere productos o servicios de una empresa, los mismos que son fundamentales para el desarrollo de las empresas. Las personas que atiende un negocio debe entender que el cliente no siempre va a tener la razón por ese motivo hay que expresar que la opinión del mismo sin ofensas para no perder al cliente, porque si los clientes no regresan a comprar baja la rentabilidad de la empresa.

\section{Factores que influyen en la satisfacción al cliente}

Existen cuatro factores básicos que influyen en la satisfacción del cliente, en los cuales se encuentran las siguientes variables que tienen relación con el producto, las actividades comerciales, con los servicios de post venta y con la cultura de la empresa (Milind \& Jagdich, 1997). Según un estudio realizado a clientes chinos de 20 supermercados diferentes, para identificar cuáles son los factores que influyen en la satisfacción del cliente (Lucero \& Ferrer, 2007). Utilizaron el modelo (Servqual) sobre la satisfacción del consumidor y calidad de servicio, encontrando como efecto del estudio ocho variables importantes sobre la satisfacción: conveniencia de la compra, entorno local, infraestructura, personal, precios, publicidad, servicio de post compra, distribución del producto. Es importante tomar en cuenta los siguientes factores al momento de determinar el nivel de satisfacción de los consumidores los cuáles son: 


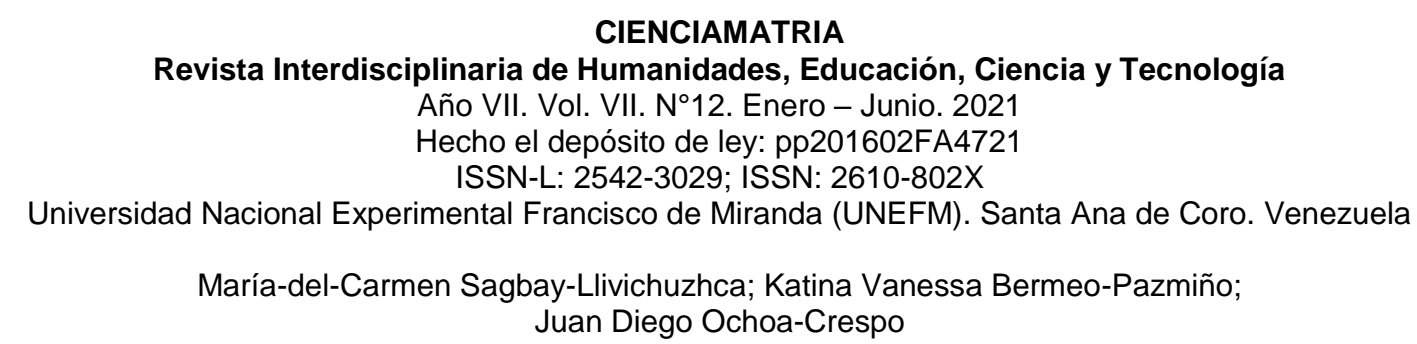

El precio es la cantidad que se paga para obtener algo, esto sucede en el momento de adquirir un producto o servicio. De manera más general, el precio es un factor principal que contribuye en la participación del mercado y la rentabilidad de la empresa. Las empresas deben revisar sus actividades operativas como está funcionando para que baje el costo, y no tomen como estrategia elevar el precio, los clientes ya se encuentran familiarizados con los productos y ya conocen sus precios que ofrece la empresa.

La publicidad es la promoción de los productos de bienes y servicios, donde su utilizan los medios de comunicación para hacer anuncios publicitarios o inserciones pagadas, con el único objetivo de captar clientes y llamar su atención (Monferrer, 2013). Las empresas deben utilizar la publicidad como estrategia para captar nuevos clientes, para dar a conocer los productos o servicios que ofrecen utilizando la tecnología.

El servicio al cliente es un factor que influye en el momento de la compra, existen varios elementos del servicio al cliente como: el contacto cara a cara, el personal que tiene relación directa con el cliente. El servicio del cliente es una relación entre consumidor y la empresa.

El personal administrativo y el personal de toda la empresa deben ser el complemento que ayude al consumidor cubrir sus necesidades. El personal que tiene contacto directo con los consumidores son el eje principal para la satisfacción cliente. Dentro del personal tenemos el factor del tiempo de respuesta a un cliente en el requerimiento de manera rápida y oportuna. Las empresas deben capacitar a sus empleados sobre temas relacionados con la atención al cliente, un cliente que no es bien atendido no vuelve a comprar y acude a la competencia, y el mismo ya no regrese otra vez (Álvarez, et al., 2020).

La localización es un factor que determina el grado de comodidad del cliente, los clientes siempre necesitan realizar sus transacciones con toda comodidad y tranquilidad (Krajewski, et al., 2000). Los consumidores son la parte fundamental de las empresas, y 


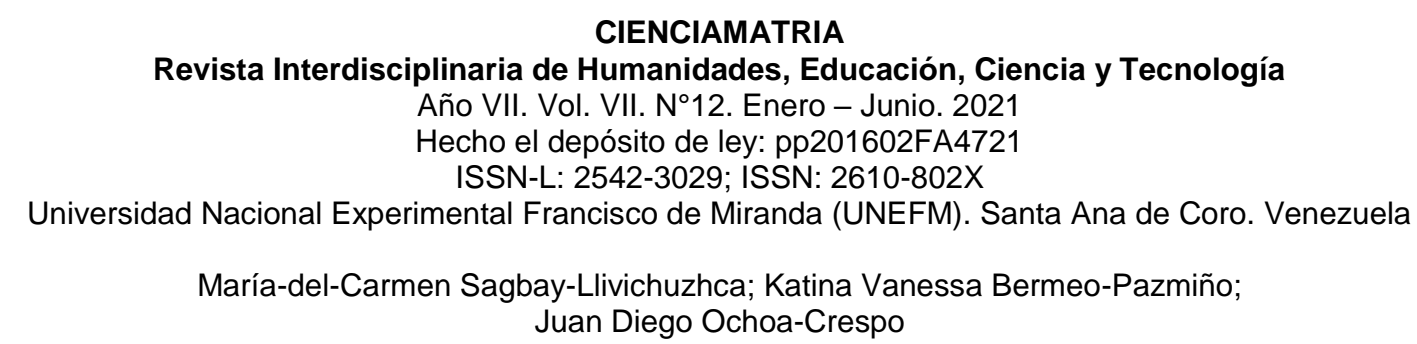

los mismos deben sentirse a gusto al momento de hacer sus compras, por eso es primordial el lugar donde se localizan las empresas.

Los consumidores que compran en los supermercados ya están familiarizados con los productos que ofrece en términos de precio, marca, calidad, etc., estos clientes se vuelven leales y sienten más confianza en el establecimiento que se encuentran (Berkowitz, 2005).

La amplia variedad de productos también influye a menudo en la imagen de las tiendas, y estos influyen en la calidad percibida de los productos que ofrecen y en las decisiones de los consumidores con respecto a dónde comprar. Estas imágenes surgen de un diseño y su entorno físico, sus estrategias de precios y la variedad de mercancías (Schiffman \& Kanuk, 2010).

Si la empresa cumple con las expectativas del cliente brindando un buen producto y un servicio excelente, este quedará satisfecho, iniciando un nuevo proceso, el de la fidelización que debe asegurar de que el cliente nos vuelva a comprar, y hacerlo en la medida de lo posible. Probablemente nos recomendarán a otros consumidores y la compra en la empresa nunca debe ser la última (Erazo \& Narváez, 2020).

Los factores que influyen en las expectativas del consumidor son recomendaciones, necesidades personales, experiencias pasadas y comunicaciones externas. Las recomendaciones son una fuente de información de personas que se sabe que son bastante creíbles, como familiares o amigos. Las necesidades personales son todas necesidades fisiológicas de seguridad y estima. Las experiencias pasadas son circunstancias vividas en el pasado que brindan conocimiento sobre el servicio o producto. Comunicaciones externas de la empresa que prometen determinados aspectos relacionados con productos o servicios que está publicitando (Fernández, 2013). 


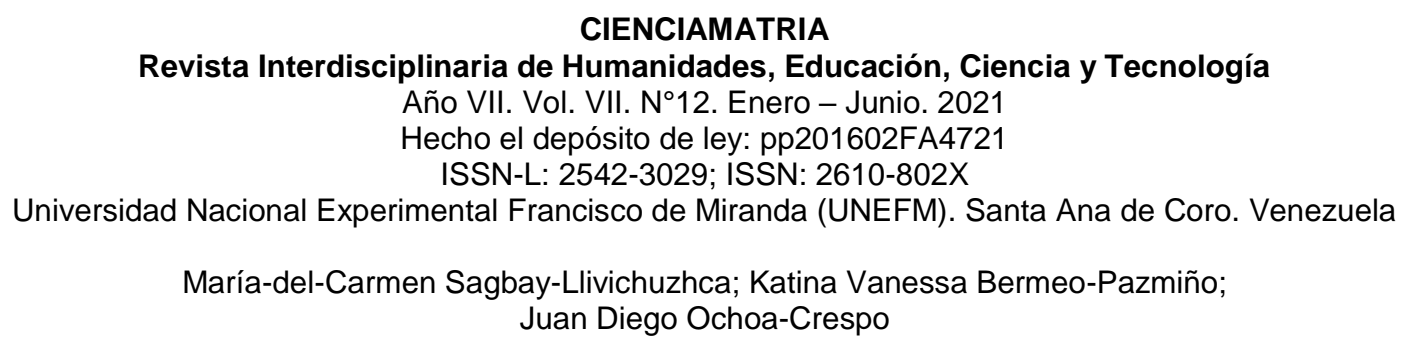

\section{Técnicas de recopilación de datos para medir la satisfacción de los clientes}

Población es todo el conjunto de elementos, finito o infinito que posee una serie de características y los mismos habitan en un lugar determinado. Muestreo su objetivo es determinar qué parte de una realidad en estudio debe examinarse para hacer inferencias sobre la población. Mediante el muestreo podemos obtener una muestra fiable de un modelo a pequeña escala de nuestro universo o población, siempre que la muestra obtenida sea representativa (Comité para el Desarrollo de la Calidad Total, 2003).

Para medir la satisfacción al cliente se realiza la recopilación de información analizando varias fuentes, las mismas que se obtienen de las fuentes internas y fuentes externas, en las fuentes internas se encuentran las personas que se desempeñan en diferentes áreas dentro de la empresa y el principal personal que tienen contacto directos con los clientes, en las fuentes externas se encuentra todo el entorno empresarial, es decir, la población que adquiere los productos o servicios de las empresas, los clientes que buscan satisfacer sus necesidades de manera satisfactoria, y las personas que tienen varios años de experiencia en varios ámbitos laborales como son los expertos, los mismo que dan su opinión según el estudio de investigación (Ávila-Sacoto, et al., 2019). 


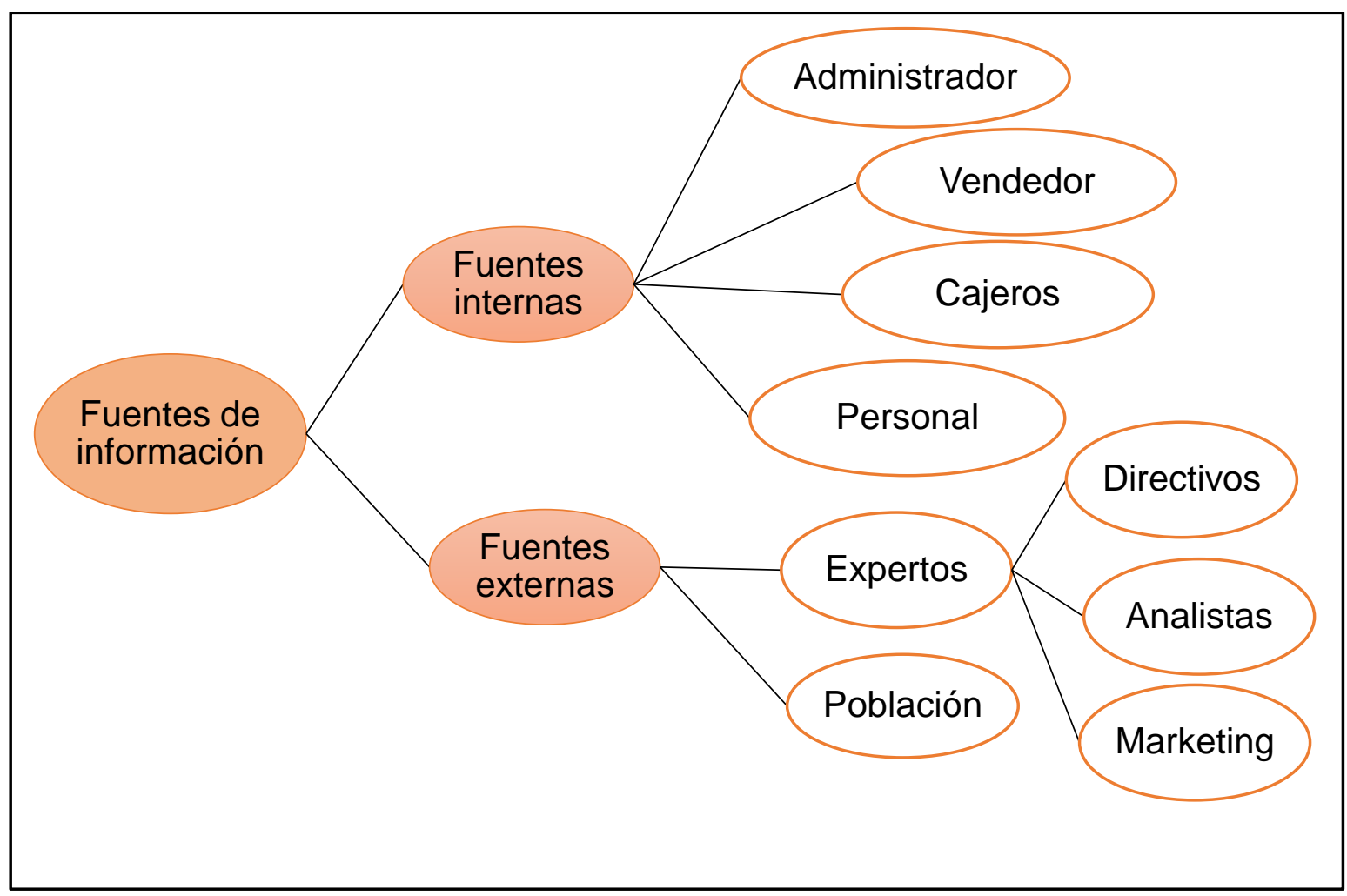

Figura 1. Fuentes internas - Fuentes externas.

Elaboración propia.

El uso de técnicas cualitativas y cuantitativas contribuye a la recopilación de información. La técnica cualitativa es una forma de llegar a obtener información relevante de los aspectos internos y profundos del individuo según la investigación, se utiliza métodos y técnicas para obtener información narrativa. La técnica cuantitativa permite cuantificar y medir la información, mediante los datos estadísticos de un entorno (Rivas \& Ildefonso, 2004).

La técnica cualitativa aprovecha las respuestas de tipo abierto, con poca cantidad de casos, los resultados se utilizan como un estudio exploratorio, en esta técnica no se pueden brindar información estadística la misma que puede generalizarse en una población más amplia. La técnica cuantitativa son los puntos de vista y opiniones que se representan en datos estadísticos, la técnica más utilizada para la obtención de la 
CIENCIAMATRIA

Revista Interdisciplinaria de Humanidades, Educación, Ciencia y Tecnología

Año VII. Vol. VII. N¹2. Enero - Junio. 2021

Hecho el depósito de ley: pp201602FA4721

ISSN-L: 2542-3029; ISSN: 2610-802X

Universidad Nacional Experimental Francisco de Miranda (UNEFM). Santa Ana de Coro. Venezuela

María-del-Carmen Sagbay-Llivichuzhca; Katina Vanessa Bermeo-Pazmiño;

Juan Diego Ochoa-Crespo

información es la entrevista. Como aparece en la Tabla 1 la técnica cualitativa y cuantitativa no son alternativas sino más bien son complementarias.

\section{Tabla 1.}

Diferencias entre las técnicas cualitativas y cuantitativas.

\begin{tabular}{|c|c|c|}
\hline & Cualitativa & Cuantitativa \\
\hline Tipo investigación & Exploratoria & Descriptiva/ estadística \\
\hline Tipo de preguntas & De final abierto (sondeo) & De final cerrado \\
\hline Cantidad de entrevistados & Pequeña & Grande \\
\hline Análisis & Subjetivo & Estadístico \\
\hline $\begin{array}{l}\text { Calificaciones } \\
\text { entrevistador }\end{array}$ & $\begin{array}{ll}\text { Necesita } & \text { una } \\
\text { preparación especial }\end{array}$ & $\begin{array}{l}\text { Menos necesidad } \\
\text { preparación especial }\end{array}$ \\
\hline $\begin{array}{l}\text { Generalización de los } \\
\text { resultados }\end{array}$ & Muy limitada & Razonable \\
\hline
\end{tabular}

Fuente: Dutka \& Mazia (1994).

La entrevista es una técnica que contribuye a satisfacer los requerimientos de interacción personal, es donde se realizan interrogantes de ciertos aspectos a sondear y más tarde de la información de los resultados se informa a las demás personas, la entrevista al ser una forma vocal de explicación interpersonal con fin de conseguir documentación relevante con relación al objetivo (Ibáñez \& López, 2004). El cuestionario consta de varias preguntas relacionadas con el tema de investigación, las mismas que deben ser claras y concisas, para que la información sea relevante y análisis de los resultados sea un aporte importante para los dueños de los supermercados (Guevara-Morocho, et al., 2019). Método Delphi es un método de prospectiva experto, que realiza un debate con un grupo de conocedores sobre el estudio de investigación, con el fin de obtener un consenso y llegar a obtener las mejores conclusiones, Este método permite llevar a cabo pronósticos 


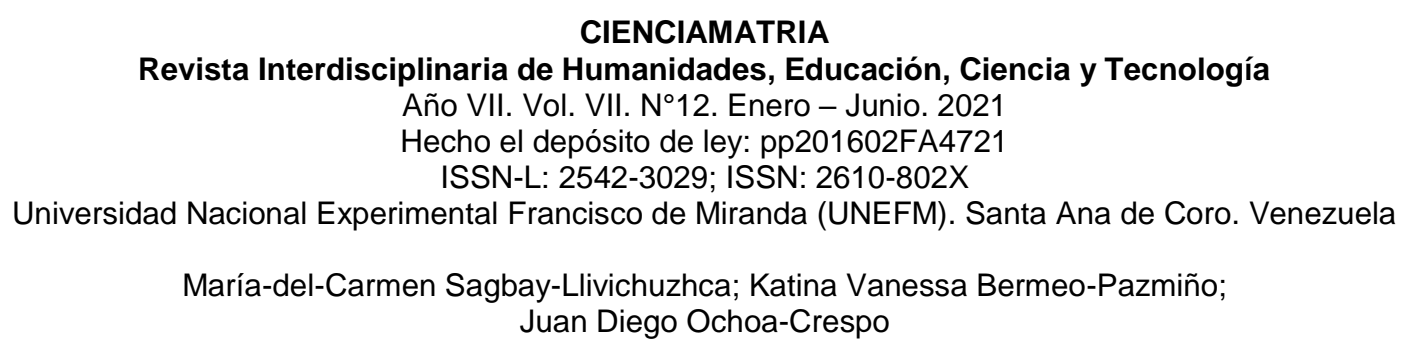

de expertos, quienes pueden estar ubicados en diferentes lugares, en el proceso de realización del método se puede utilizar varios elementos como es el de la circulación en cada repetición se presenta los cuestionarios a los expertos, el cuestionario es un documento que consta de preguntas e información de resultados anteriores, panel conjunto de experto con varios años de experiencia según el tema de investigación, moderador personas encargada de todo el proceso de recoger las respuestas y preparar el cuestionario (Llorens, 2005). En la aplicación del método Delphi existen tres fases tradicionales que generan distintos niveles de discurso:

a) Nivel distribucional es aquella donde cada experto crea su propio discurso.

b) Nivel relacional donde hubo un intercambio de opiniones anteriores.

c) Nivel integrativo que originó un consenso discursivo y con el resultado anterior construyó el documento para la segunda ronda (Izquierdo \& Ghiggi, 2007).

Los principios básicos de un estudio del método Delphi son: 1) Es un proceso iterativo: se realizan rondas sucesivas para que los participantes revisen sus opiniones; 2) Requiere retroalimentación: los paneles de expertos reciben valoraciones de los participantes antes de empezar la ronda, para dar sus criterios al grupo y ofrecer nuevamente su juicio; 3) Requiere del anonimato para las respuestas individuales. 4) Construcción de un consenso: este es un acuerdo general de grupo a partir del procesamiento estadístico de las diferencias y coincidencias entre las apreciaciones individuales y sus modificaciones a través de las rondas. 
CIENCIAMATRIA

Revista Interdisciplinaria de Humanidades, Educación, Ciencia y Tecnología

Año VII. Vol. VII. N¹2. Enero - Junio. 2021

Hecho el depósito de ley: pp201602FA4721

ISSN-L: 2542-3029; ISSN: 2610-802X

Universidad Nacional Experimental Francisco de Miranda (UNEFM). Santa Ana de Coro. Venezuela

María-del-Carmen Sagbay-Llivichuzhca; Katina Vanessa Bermeo-Pazmiño;

Juan Diego Ochoa-Crespo

Fase de preparación

Fase de consulta

Fase de consenso
- Selección de expertos

- Preparación del instrumento

- Decisión de la vía de consulta
- Realización de las rondas

- Procesamiento estadístico sucesivo

- Retroalimentación

Figura 2. Etapas del Método Delphi.

Fuente: García \& Suárez (2013).

Este método contribuye a dar solución al estudio de investigación teniendo respuestas favorables y las mismas que deben ser aplicadas en las empresas, aun mas si la información brindada es de personas con un alto nivel de experiencia que dan sus opiniones con el fin de que los resultados sean analizados y puesto en marcha. Las empresas deben utilizar este tipo de metodología para que conozcan que está sucediendo en el negocio y puedan dar solución al mismo en su debido tiempo (PaltánAngumba, et al., 2020). 
CIENCIAMATRIA

Revista Interdisciplinaria de Humanidades, Educación, Ciencia y Tecnología

Año VII. Vol. VII. N¹2. Enero - Junio. 2021

Hecho el depósito de ley: pp201602FA4721

ISSN-L: 2542-3029; ISSN: 2610-802X

Universidad Nacional Experimental Francisco de Miranda (UNEFM). Santa Ana de Coro. Venezuela

María-del-Carmen Sagbay-Llivichuzhca; Katina Vanessa Bermeo-Pazmiño; Juan Diego Ochoa-Crespo

\section{MÉTODO}

El tipo de investigación es descriptivo con diseño no experimental de campo, a través de la descripción de hechos de cohorte transversal, debido a que la información para el análisis se recopiló en único momento mediante encuesta y cuestionarios. Para el desarrollo de la investigación se utilizó el muestreo por conveniencia a una población de 59 clientes de supermercados del Cantón Sígsig - Ecuador, siendo analizada mediante estadística descriptiva y presentada en frecuencias, porcentajes y gráficos.

\section{RESULTADOS}

Las personas realizan sus compras dependiendo el nivel de ingresos, generalmente la mayor parte de las personas del Cantón Sígsig trabajan realizando sombreros de paja toquilla. Se puede observar que, del total de encuestados, el $54 \%$ realizan sus compras cada semana, se podría decir que la compra es más frecuente cada semana por que las personas venden sus sombreros para poder adquirir los productos en algunos casos, el $30 \%$ compran cada 15 días y el $15 \%$ una sola vez al mes.

\section{Tabla 2.}

Frecuencia de compras en los supermercados.

\begin{tabular}{lcc}
\hline Frecuencia de compra & $\begin{array}{c}\mathrm{N}^{\circ} \text { de } \\
\text { personas }\end{array}$ & Porcentaje \\
\hline Cada semana & 32 & 54 \\
Una vez cada 15 días & 18 & 31 \\
Una vez al mes & 9 & 15 \\
\multicolumn{1}{c}{ Total } & 59 & 100 \\
\hline
\end{tabular}


CIENCIAMATRIA

Revista Interdisciplinaria de Humanidades, Educación, Ciencia y Tecnología

Año VII. Vol. VII. N¹2. Enero - Junio. 2021

Hecho el depósito de ley: pp201602FA4721

ISSN-L: 2542-3029; ISSN: 2610-802X

Universidad Nacional Experimental Francisco de Miranda (UNEFM). Santa Ana de Coro. Venezuela

María-del-Carmen Sagbay-Llivichuzhca; Katina Vanessa Bermeo-Pazmiño;

Juan Diego Ochoa-Crespo

Los ingresos mensuales de los consumidores, el $69 \%$ de los consumidores tienen un ingreso familiar mensual aproximado entre $\$ 100$ y $\$ 300$ dólares promedio, el $22 \%$ tienen ingresos entre $\$ 301$ y $\$ 500$, el $5 \%$ obtienen un ingreso mensual entre $\$ 501$ y $\$ 700$, el $3 \%$ tienen ingresos entre $\$ 901$ y $\$ 1100$.

\section{Tabla 3.}

Ingreso mensual aproximado de los consumidores del Cantón Sígsig.

\begin{tabular}{ccc}
\hline $\begin{array}{c}\text { Ingreso } \\
\text { mensual }\end{array}$ & $\begin{array}{c}\mathrm{N}^{\circ} \text { de } \\
\text { personas }\end{array}$ & Porcentaje \\
\hline$\$ 100-\$ 300$ & 41 & 69,5 \\
$\$ 100-\$ 300$ & 13 & 22 \\
$\$ 501-\$ 700$ & 2 & 5,1 \\
$\$ 901-\$ 1100$ & 3 & 3,4 \\
Total & 59 & 100 \\
\hline
\end{tabular}

Factores que consideran las personas al momento de elegir su compra, el factor muy importante según las repuestas de los encuestadores es la buena atención, teniendo como importante la calidad de los productos, en el factor medianamente importante se encuentra el precio, en mínima importancia la variedad del producto y con nada de importancia los factores de facilidad de pago, tiempo de espera y la marca.

Aspectos considerados desde un nivel de nada de importancia hasta el muy importante, teniendo como muy importante la limpieza de local que viene a ser la imagen de la empresa, como importante está el horario de atención, medianamente importante estanterías organizadas, en el aspecto de mínima de importancia se encuentra la variedad de categorías del producto, y con nada de importancia se encuentran los siguientes aspectos ubicación en el centro o en las afueras, parqueadero y la variedad de marcas. 


\section{CIENCIAMATRIA}

Revista Interdisciplinaria de Humanidades, Educación, Ciencia y Tecnología

Año VII. Vol. VII. N¹2. Enero - Junio. 2021

Hecho el depósito de ley: pp201602FA4721

ISSN-L: 2542-3029; ISSN: 2610-802X

Universidad Nacional Experimental Francisco de Miranda (UNEFM). Santa Ana de Coro. Venezuela

María-del-Carmen Sagbay-Llivichuzhca; Katina Vanessa Bermeo-Pazmiño; Juan Diego Ochoa-Crespo

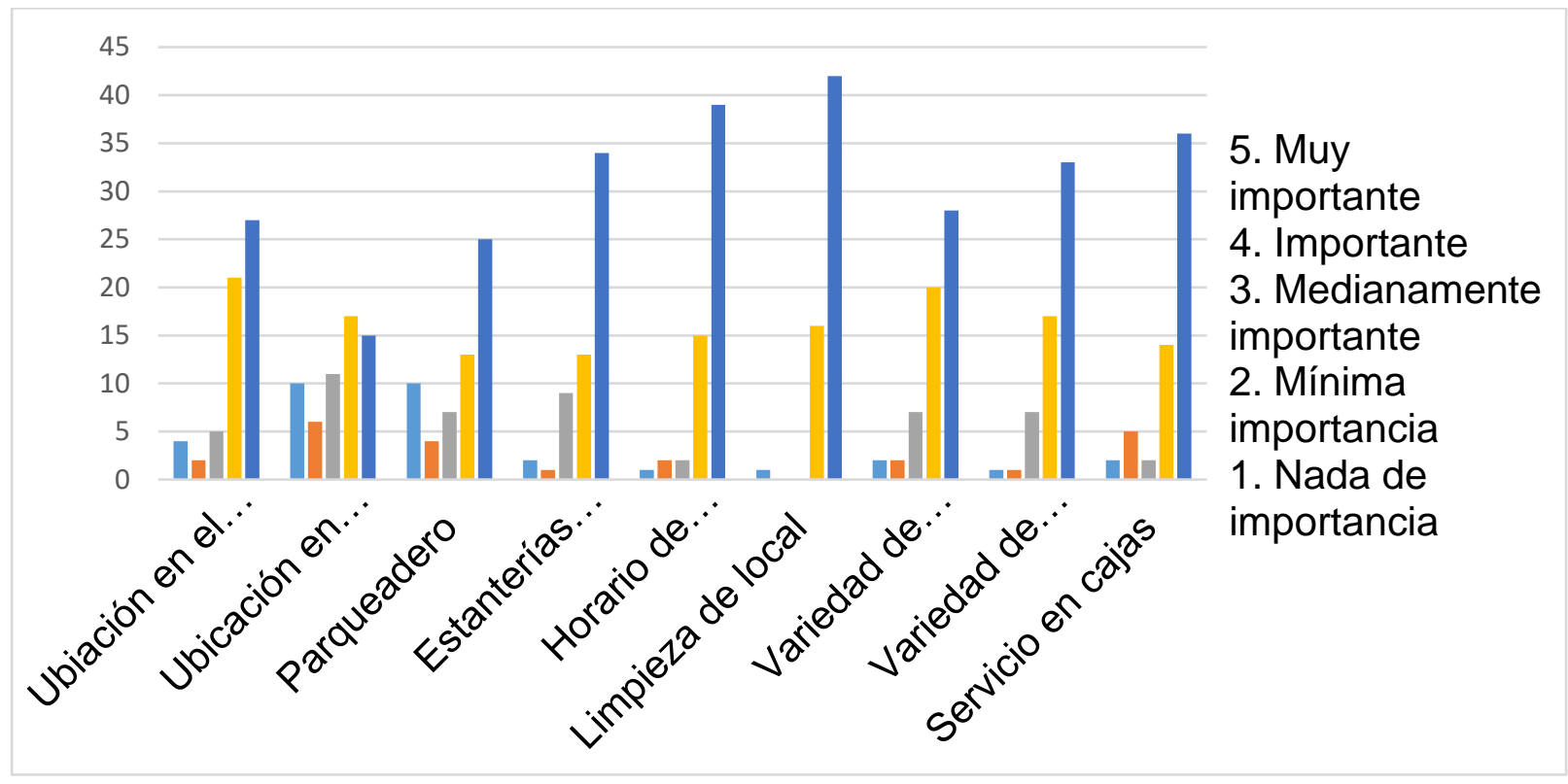

Figura 3. Aspectos más importantes de un supermercado

Los supermercados al ofrecer productos masivos contribuyen con los usuarios para que no tengan que viajar a otros lugares de donde viven a comprar sus productos, y ahora tiene la opción de elegir varios supermercados para sus compras, del total de encuestados $38 \%$ compra sus productos en el supermercado Maxi Market, el $36 \%$ en El Sigsal, el $18 \%$ en el Mini Market Victoriano López, el $6 \%$ Comisariato del Pueblo, y $2 \%$ en el SuperMarket Super Surtido. 


\section{CIENCIAMATRIA}

Revista Interdisciplinaria de Humanidades, Educación, Ciencia y Tecnología

Año VII. Vol. VII. N¹2. Enero - Junio. 2021

Hecho el depósito de ley: pp201602FA4721

ISSN-L: 2542-3029; ISSN: 2610-802X

Universidad Nacional Experimental Francisco de Miranda (UNEFM). Santa Ana de Coro. Venezuela

María-del-Carmen Sagbay-Llivichuzhca; Katina Vanessa Bermeo-Pazmiño;

Juan Diego Ochoa-Crespo

Tabla 4.

Supermercados de preferencia según el consumidor.

\begin{tabular}{lcc}
\hline \multicolumn{1}{c}{ Supermercados } & $\begin{array}{c}\mathrm{N}^{\circ} \text { de } \\
\text { personas }\end{array}$ & Porcentaje \\
\hline Maxi Market & 22 & 38 \\
$\begin{array}{l}\text { Supermercado El Sigsal } \\
\text { Mini Market Victoriano }\end{array}$ & 19 & 36 \\
López & 11 & 18 \\
$\begin{array}{l}\text { Comisariato del Pueblo } \\
\text { SuperMarket Super }\end{array}$ & 5 & 6 \\
\begin{tabular}{l} 
Surtido \\
\multicolumn{1}{c}{ Total }
\end{tabular} & 2 & 2 \\
\hline
\end{tabular}

La tecnología es muy utilizada hoy en día por muchas personas, y son los medios que las empresas deben utilizar para realizar publicidad de los productos que ofrece, del total de encuestados el $70 \%$ utilizan el internet para informarse, el $25 \%$ utiliza el radio y el $5 \%$ la televisión. 


\section{CIENCIAMATRIA}

Revista Interdisciplinaria de Humanidades, Educación, Ciencia y Tecnología

Año VII. Vol. VII. N¹2. Enero - Junio. 2021

Hecho el depósito de ley: pp201602FA4721

ISSN-L: 2542-3029; ISSN: 2610-802X

Universidad Nacional Experimental Francisco de Miranda (UNEFM). Santa Ana de Coro. Venezuela

María-del-Carmen Sagbay-Llivichuzhca; Katina Vanessa Bermeo-Pazmiño; Juan Diego Ochoa-Crespo

Tabla 5.

Medios tecnologías que usan los clientes para informarse.

\begin{tabular}{|c|c|c|}
\hline Medios informativos & $\begin{array}{c}\mathrm{N}^{\circ} \mathrm{de} \\
\text { personas }\end{array}$ & Porcentaje \\
\hline Internet & 40 & 70 \\
\hline Radio & 15 & 25 \\
\hline Televisión & 4 & 5 \\
\hline Total & 59 & 100 \\
\hline
\end{tabular}

Las preferencias y gustos son importantes en los negocios, por contribuyen con la satisfacción de los clientes, para este aspecto los individuos encuestados concuerdan que los siguientes aspectos son los principales; los productos surtidos es lo que más les gustaría de los supermercados, el aspecto de las ofertas que es muy utilizado en varios negocios, los cupones de descuentos es la forma de llamar la atención de los clientes, pasillos amplios los clientes siempre buscan la comodidad; como aspectos secundarios se encuentran la infraestructura amplia, la publicidad novedosa, regalos por compras y los descuentos. 


\section{CIENCIAMATRIA}

Revista Interdisciplinaria de Humanidades, Educación, Ciencia y Tecnología

Año VII. Vol. VII. N¹2. Enero - Junio. 2021

Hecho el depósito de ley: pp201602FA4721 ISSN-L: 2542-3029; ISSN: 2610-802X

Universidad Nacional Experimental Francisco de Miranda (UNEFM). Santa Ana de Coro. Venezuela

María-del-Carmen Sagbay-Llivichuzhca; Katina Vanessa Bermeo-Pazmiño; Juan Diego Ochoa-Crespo

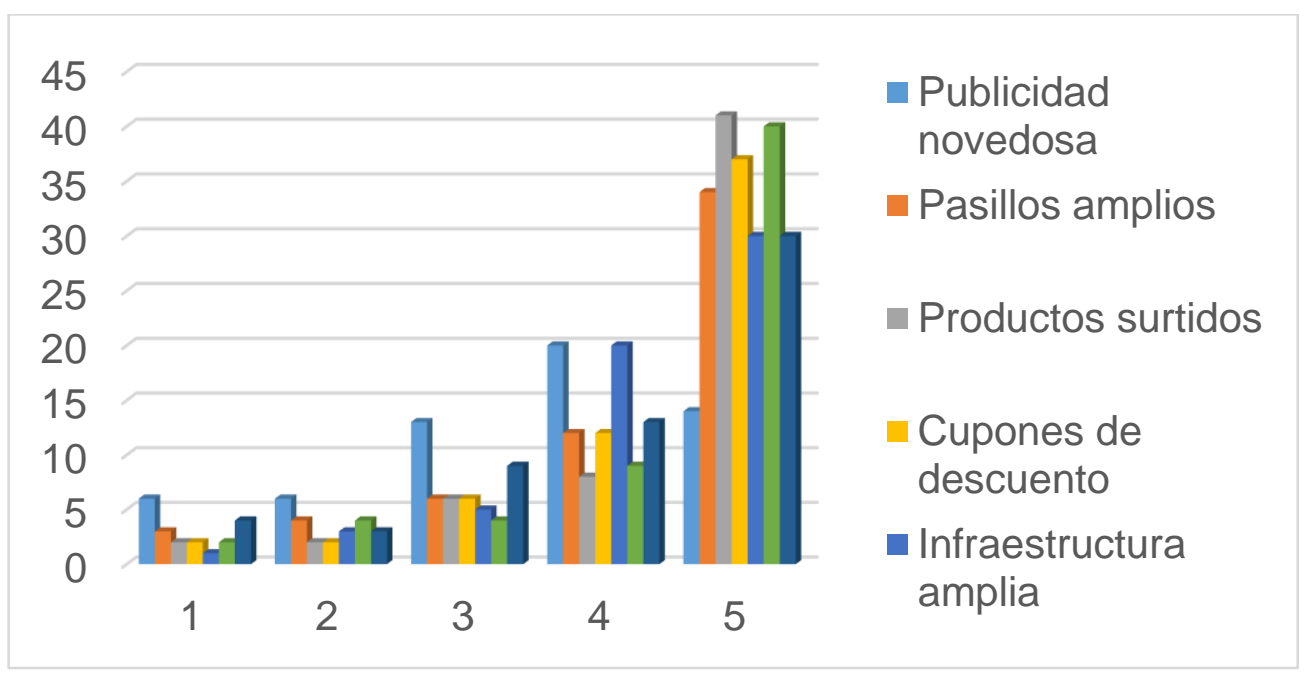

Figura 4. Aspectos que debe tener un supermercado.

\section{PROPUESTA}

Se propone analizar el nivel de satisfacción de los consumidores del Cantón Sígsig de la provincia de Azuay, teniendo como fuente interna a los usuarios, los propietarios y empleados del supermercado, como fuentes externas a experto y la población del cantón, se aplicará técnicas cualitativas y cuantitativas con fin de determinar cuáles son los factores que están influyendo en la compra que realizan los consumidores e implementar acciones de mejora. 
CIENCIAMATRIA

Revista Interdisciplinaria de Humanidades, Educación, Ciencia y Tecnología

Año VII. Vol. VII. N¹2. Enero - Junio. 2021

Hecho el depósito de ley: pp201602FA4721

ISSN-L: 2542-3029; ISSN: 2610-802X

Universidad Nacional Experimental Francisco de Miranda (UNEFM). Santa Ana de Coro. Venezuela

María-del-Carmen Sagbay-Llivichuzhca; Katina Vanessa Bermeo-Pazmiño; Juan Diego Ochoa-Crespo

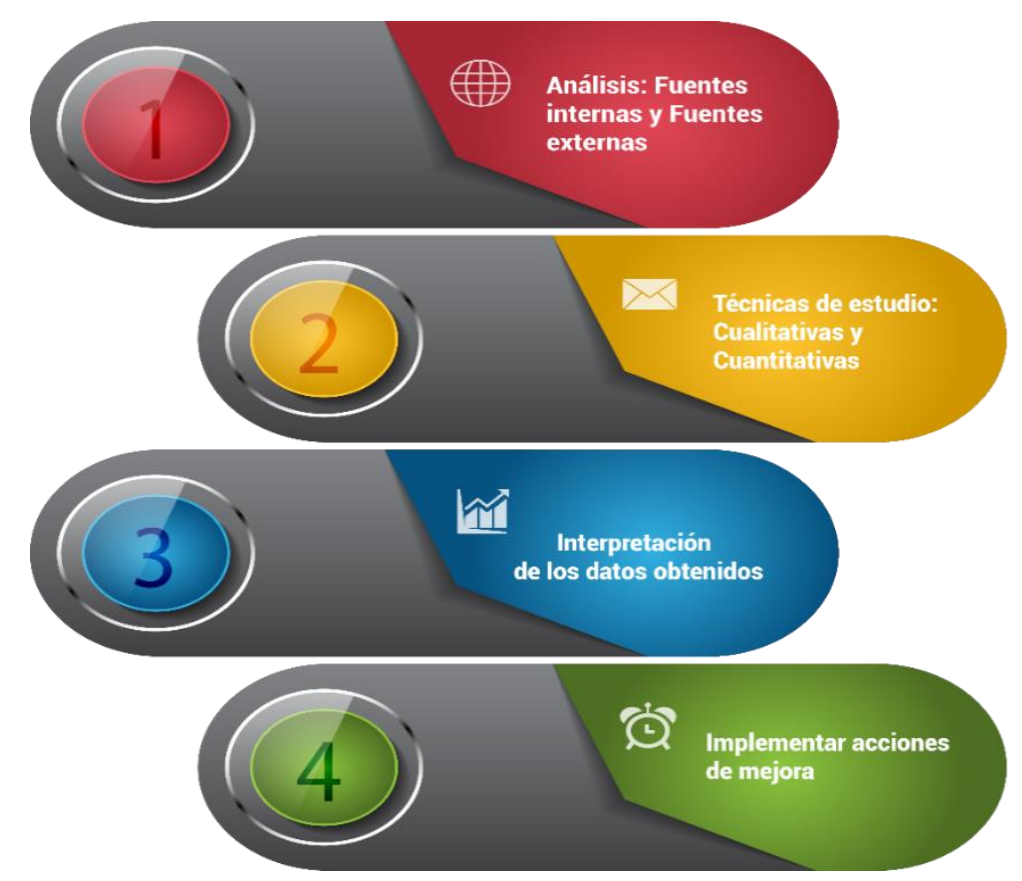

Figura 5. Análisis- Implementación de acciones de mejora. Elaboración propia.

\section{Análisis de fuentes internas y externas}

El éxito de las empresas son los clientes, los clientes son la principal fuente interna dentro de la investigación, así mismo están los administradores y empleados que trabajan en los supermercados, son ellos los que deben estar atentos a los requerimientos de los consumidores y las opiniones que den los mismos sobre los productos que adquieren del establecimiento. En el caso de las fuentes externas están los expertos que han realizado investigaciones, tienen más experiencia y emiten ideas relevantes para encontrar solución a las investigaciones.

Se realizó varias entrevistas a empleados que trabajan en los supermercados del Cantón Sígsig, los mismos cuentan con varios años de experiencia, la gran mayoría de empleados manifiestan dos puntos importantes que son capacitados solo cuando 


\section{CIENCIAMATRIA}

Revista Interdisciplinaria de Humanidades, Educación, Ciencia y Tecnología

Año VII. Vol. VII. N¹2. Enero - Junio. 2021

Hecho el depósito de ley: pp201602FA4721

ISSN-L: 2542-3029; ISSN: 2610-802X

Universidad Nacional Experimental Francisco de Miranda (UNEFM). Santa Ana de Coro. Venezuela

María-del-Carmen Sagbay-Llivichuzhca; Katina Vanessa Bermeo-Pazmiño; Juan Diego Ochoa-Crespo

ingresan a laborar, que los clientes se quejan por los precios, y se pudo analizar otras dimensiones importantes.

En la siguiente tabla se sintetiza algunas dimensiones sobre satisfacción al cliente realizado a los empleados de los supermercados.

Tabla 6.

Entrevista a los empleados.

\begin{tabular}{|c|c|}
\hline DIMENSIONES & CRITERIOS \\
\hline \multirow[t]{4}{*}{ Dimensión de capacidad } & Capacitación del sistema \\
\hline & Orden y limpieza de la área de trabajo cada \\
\hline & 15 días \\
\hline & Atención al cliente \\
\hline Dimensión estrategias de & \\
\hline \multirow[t]{3}{*}{ marketing } & No realizan publicidad continuamente \\
\hline & Publicidad solo en la red social de \\
\hline & Facebook \\
\hline \multirow[t]{5}{*}{ Dimensión de servicio al cliente } & Personal sin experiencia en cobros \\
\hline & Atención mas rápida \\
\hline & Molestias de los clientes por el tiempo de \\
\hline & espera, para realizar sus cancelaciones \\
\hline & Carácter del personal que atiende \\
\hline \multirow[t]{2}{*}{ Dimension inconformidades } & Insuficiente stocks \\
\hline & Precios altos \\
\hline
\end{tabular}

Fuente: Elaboración propia. 
CIENCIAMATRIA

Revista Interdisciplinaria de Humanidades, Educación, Ciencia y Tecnología

Año VII. Vol. VII. N¹2. Enero - Junio. 2021

Hecho el depósito de ley: pp201602FA4721

ISSN-L: 2542-3029; ISSN: 2610-802X

Universidad Nacional Experimental Francisco de Miranda (UNEFM). Santa Ana de Coro. Venezuela

María-del-Carmen Sagbay-Llivichuzhca; Katina Vanessa Bermeo-Pazmiño;

Juan Diego Ochoa-Crespo

A continuación, se presenta información más relevante de la entrevista realizada a los administradores o dueños de los supermercados del Cantón Sígsig sobre temas relacionados con los colaboradores, clientes y sobre el entorno del establecimiento en general.

Tabla 7.

Entrevista a los administradores o dueños de los supermercados.

\begin{tabular}{lll}
\hline DIMENSIONES & \multicolumn{1}{c}{ CRITERIOS } \\
\hline $\begin{array}{l}\text { Dimension infraestructura } \\
\text { Dimension quejas }\end{array}$ & yodificación del establecimiento \\
sugerencias & $\begin{array}{l}\text { Ningún supermercado maneja esa técnica } \\
\text { No realizan programas de innovación y } \\
\text { Dimensión de estrategias }\end{array}$ & mejora \\
\hline
\end{tabular}

Fuente: Elaboración propia.

\section{Método Delphi}

Teniendo ya determinado las fuentes de información del estudio a investigar sobre la satisfacción de los consumidores, se plantea realizar estudio con los expertos utilizando el método Delphi, este método permitirá conocer las opiniones de los expertos utilizando un cuestionario.

Cuestionario

El panel de expertos que contestó el cuestionario Delphi se compuso por 15 individuos en su gran mayoría hombres, con experiencia demostrada en el sector se puede visualizar la información en la figura 7 . 


\section{CIENCIAMATRIA}

Revista Interdisciplinaria de Humanidades, Educación, Ciencia y Tecnología

Año VII. Vol. VII. N¹2. Enero - Junio. 2021

Hecho el depósito de ley: pp201602FA4721

ISSN-L: 2542-3029; ISSN: 2610-802X

Universidad Nacional Experimental Francisco de Miranda (UNEFM). Santa Ana de Coro. Venezuela

María-del-Carmen Sagbay-Llivichuzhca; Katina Vanessa Bermeo-Pazmiño;

Juan Diego Ochoa-Crespo

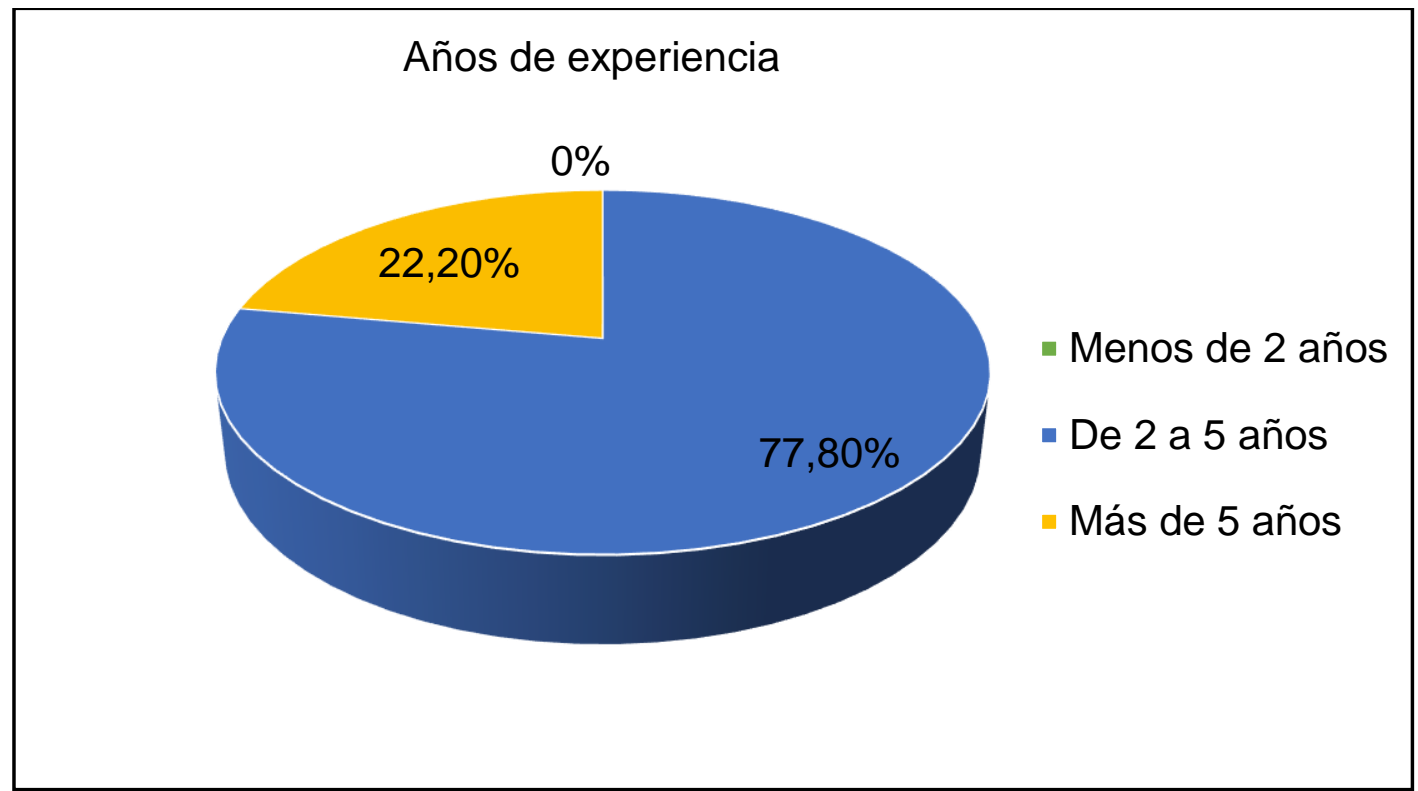

Figura 6. Años de experiencia en el sector de panel de expertos.

El espectro de cargos en que se desempeñaban los integrantes del panel en el momento de la encuesta fue considerablemente variado. Abarcó desde altos directivos hasta jefes de equipos y responsables comerciales que tiene contacto directo con los clientes sobre objeto de estudio.

\section{Tabla 8.}

Cargo del panel de expertos.

\begin{tabular}{lc}
\hline Cargos & $\%$ \\
\hline Directivos & $11,10 \%$ \\
Gerente & $22,20 \%$ \\
Servicios & $33,30 \%$ \\
Con personal a su cargo & $33,30 \%$ \\
\hline
\end{tabular}

Fuente: Elaboración propia. 
CIENCIAMATRIA

Revista Interdisciplinaria de Humanidades, Educación, Ciencia y Tecnología

Año VII. Vol. VII. N¹2. Enero - Junio. 2021

Hecho el depósito de ley: pp201602FA4721

ISSN-L: 2542-3029; ISSN: 2610-802X

Universidad Nacional Experimental Francisco de Miranda (UNEFM). Santa Ana de Coro. Venezuela

María-del-Carmen Sagbay-Llivichuzhca; Katina Vanessa Bermeo-Pazmiño;

Juan Diego Ochoa-Crespo

\section{Principales motivos y factores que influyen en la satisfacción de los clientes}

Principales motivos por lo que los clientes cambian de supermercados. Para comenzar a dar respuesta a esta cuestión hemos formulado 5 cuestiones que los diferentes expertos han respondido siguiendo las pautas del método Delphi.

Se muestran los resultados en la siguiente tabla del análisis Delphi que da respuesta a la primera cuestión.

Tabla 9.

Principales motivos que influyen en los clientes ir a la competencia.

\begin{tabular}{llc}
\hline $\begin{array}{l}\text { Principales motivos que influyen en los } \\
\text { clientes }\end{array}$ & $\begin{array}{l}\text { Valoración } \mathbf{0} \text { a } \mathbf{5} \\
\text { ronda } \mathbf{1} \text { (0 min, } \mathbf{5}\end{array}$ & $\begin{array}{c}\text { Valoración } \mathbf{0} \text { a } \mathbf{5} \\
\text { ronda } \mathbf{1} \text { (0 min, } \mathbf{5}\end{array}$ \\
\hline Dejar de depender de un solo supermercado & 3,22 & 3,21 \\
Precios más bajos & 4,22 & 4,25 \\
Baja atención al cliente & 4,11 & 4,12 \\
Baja oferta & 3,78 & 4 \\
Incumplimiento de los requerimientos & 3,78 & 3,8 \\
\hline
\end{tabular}

Fuente: Elaboración propia.

Esta cuestión introduce el concepto servicio de servicios al cliente. Los principales clientes de los supermercados se mantienen fieles a su supermercado de preferencia si la atención es personalizada.

Los factores que influyen a los clientes para que regresen a comprar son varios y los mismos se detallan en la siguiente tabla. 


\section{CIENCIAMATRIA}

Revista Interdisciplinaria de Humanidades, Educación, Ciencia y Tecnología

Año VII. Vol. VII. N¹2. Enero - Junio. 2021

Hecho el depósito de ley: pp201602FA4721

ISSN-L: 2542-3029; ISSN: 2610-802X

Universidad Nacional Experimental Francisco de Miranda (UNEFM). Santa Ana de Coro. Venezuela

María-del-Carmen Sagbay-Llivichuzhca; Katina Vanessa Bermeo-Pazmiño;

Juan Diego Ochoa-Crespo

Tabla 10.

Factores que motivan a los clientes a repetir sus compras en los supermercados.

\begin{tabular}{llc}
\hline $\begin{array}{l}\text { Factores que motivan } \\
\text { repetir la compra }\end{array}$ & $\begin{array}{l}\text { Valoración } \mathbf{0} \text { a } \mathbf{5} \\
\text { ronda } \mathbf{1} \text { (0 } \mathbf{~ m i n , ~ 5 ~}\end{array}$ & $\begin{array}{c}\text { Valoración } \mathbf{0} \text { a 5 } \\
\text { ronda } \mathbf{1} \text { (0 min, 5 }\end{array}$ \\
\hline Ubicación & 3,89 & 4 \\
Infraestructura amplia & 4,33 & 4,29 \\
Calidad & 4,22 & 4,21 \\
Publicidad novedosa & 3,33 & 3,32 \\
Atención al cliente & 4,22 & 4 \\
Productos surtidos & 4,22 & 4,23 \\
Pasillos amplios & 3,56 & 3,6 \\
\hline
\end{tabular}

Fuente: Elaboración propia. 
CIENCIAMATRIA

Revista Interdisciplinaria de Humanidades, Educación, Ciencia y Tecnología

Año VII. Vol. VII. N¹2. Enero - Junio. 2021

Hecho el depósito de ley: pp201602FA4721

ISSN-L: 2542-3029; ISSN: 2610-802X

Universidad Nacional Experimental Francisco de Miranda (UNEFM). Santa Ana de Coro. Venezuela

María-del-Carmen Sagbay-Llivichuzhca; Katina Vanessa Bermeo-Pazmiño; Juan Diego Ochoa-Crespo

\section{Implementar acciones de mejora}

Los clientes pueden realizar quejas o sugerencias al momento que tengan un inconveniente, procederá a escribir y colocar el documento en el buzón que se encuentre en el establecimiento, el mismo que debe estar en un lugar visible.

Formulario de Quejas / Reclamos /Sugerencias

Este formulario es válido para quejas, reclamos y sugerencias referidas a la atención al cliente.

Fecha:

Anónimo:

Nombre (Opcional):

\begin{tabular}{|l|l|l|l|}
\hline Queja $\square$ & Reclamo $\square$ & Sugerencia $\quad \square$ \\
\hline & & & \\
& & & \\
& & & \\
& & & \\
& & & \\
\end{tabular}

Figura 7. Formulario de quejas y sugerencias.

Los supermercados deben capacitar al personal que labora dentro de la empresa, haciendo relevancia en el aspecto de atención al cliente, los clientes son la fuente vital de las empresas y los mismos deben ser atendido de la mejor manera para que el nivel de satisfacción se convierta en una satisfacción satisfecha. 
CIENCIAMATRIA

Revista Interdisciplinaria de Humanidades, Educación, Ciencia y Tecnología

Año VII. Vol. VII. N¹2. Enero - Junio. 2021

Hecho el depósito de ley: pp201602FA4721

ISSN-L: 2542-3029; ISSN: 2610-802X

Universidad Nacional Experimental Francisco de Miranda (UNEFM). Santa Ana de Coro. Venezuela

María-del-Carmen Sagbay-Llivichuzhca; Katina Vanessa Bermeo-Pazmiño; Juan Diego Ochoa-Crespo

\section{Tabla 11.}

Capacitación a los colaboradores de los supermercados.

\begin{tabular}{|c|c|}
\hline \multicolumn{2}{|c|}{$\begin{array}{c}\text { CAPACITACIÓN FUENTES INTERNAS DEL } \\
\text { SUPERMERCADO }\end{array}$} \\
\hline $\begin{array}{l}\text { Personal a capacitar: } \\
\text { - Administrador } \\
\text { - Cajeros } \\
\text { - Vendedores } \\
\text { - Empleados } \\
\text { - Guardia }\end{array}$ & \\
\hline Actividades a desarrollar & $1 \mathrm{vez}$ al mes \\
\hline Atención al cliente & 1 hora \\
\hline Motivación & 1 hora \\
\hline Orden y limpieza & 1 hora \\
\hline Ubicación de productos & 1 hora \\
\hline
\end{tabular}

Fuente: Elaboración propia.

\section{CONCLUSIONES}

Los supermercados del Cantón Sígsig no dan una buena atención hacia los clientes, los clientes esperan que les atiendan con un saludo, una atención personalizada, amabilidad y cortesía. Los clientes realizan sus compras los fines de semana y por la demanda que esto incurre, hace que los colaboradores atiendan de la mejor manera a los clientes.

Según la información proporcionada se pudo constatar que los colaboradores no han recibido la capacitación debida, y por ende la actitud del colaborador no es la adecuada al momento de resolver alguna queja que tenga el cliente, por el tema del COVID-19 (año 2020) los supermercados han optado por entregar los pedidos en los domicilios de los 


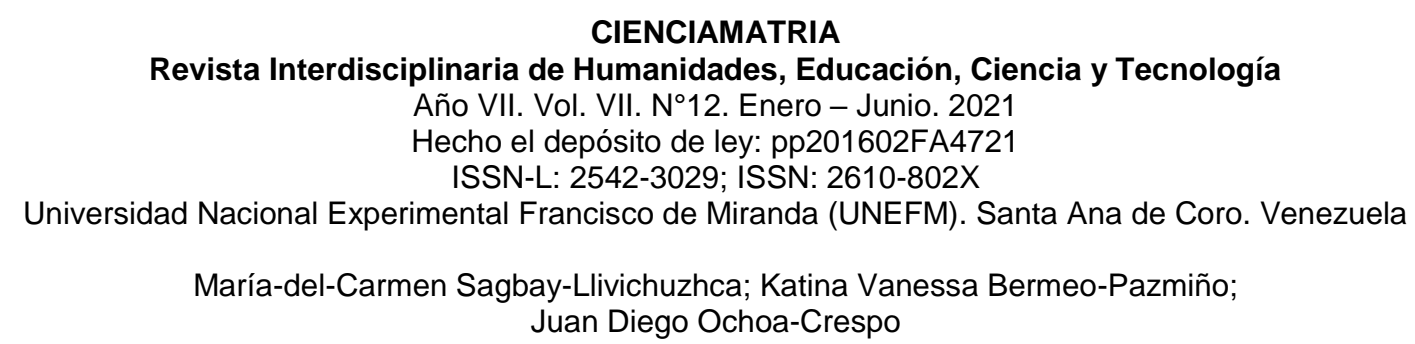

clientes, esto ha ocasionado malestar en los clientes por el tiempo de espera o por equivocaciones en los productos.

De la información obtenida de los clientes se pudo analizar que la mayoría de los clientes utilizan el internet como medio de información, pero los supermercados no realizan publicidad constante en las redes sociales y otros supermercados que no realizan ningún tipo de publicidad, los supermercados deben utilizar esto medios tecnológicos como una estrategia de marketing para captar nuevos clientes y difundir información sobre los productos que ofrecen.

Los supermercados deben emplear programas de innovación o mejora continua en los establecimientos, en la encuesta realizada a los clientes se constató que los clientes buscan la comodidad para realizar sus transacciones y que el lugar sea amplio.

\section{REFERENCIAS CONSULTADAS}

Álvarez, C., Narváez, C., Erazo, J., \& Luna, K. (2020). Lógica difusa como herramienta de evaluación del portafolio de inversiones en el sector cooperativo del Ecuador [Fuzzy logic as an investment portfolio evaluation tool in Ecuador's cooperative sector] Revista Espacios, 41(36). Obtenido de https://n9.cl/bai6c

Ávila-Sacoto, E., Erazo-Álvarez, J. C., Narváez-Zurita, C. I., \& Erazo-Álvarez, C. A. (2019). Estrategias de marketing digital 2.0 para la generación de ingresos en Pymes de servicios. [Digital Marketing 2.0 strategies for generating income in service Pymes] Recuperado de: https://n9.cl/yz442. CIENCIAMATRIA, 5(1), 187214. https://doi.org/10.35381/cm.v5i1.264

Berkowitz, D. (2005). Hispanic consumers, store loyalty and brand preference. J Target Meas Anal Mark 14, 9-24. https://doi.org/10.1057/palgrave.jt.5740166

Bernal, V., Matovelle, M., Ordoñez, C., \& Ordoñez, M. (2020). Gestión de calidad del capital humano en la Universidad Católica de Cuenca [Quality management of human capital at the Catholic University of Cuenca]. Revista Arbitrada Interdisciplinaria Koinonía, 5(3), 125-162. http://dx.doi.org/10.35381/r.k.v5i3.892

Bowersox, Closs, \& Cooper. (2007). Administración y logística en la cadena suministros [Supply chain management and logistics]. Mexico: McGraw-HillInteramericana. 
CIENCIAMATRIA

Revista Interdisciplinaria de Humanidades, Educación, Ciencia y Tecnología

Año VII. Vol. VII. N¹2. Enero - Junio. 2021

Hecho el depósito de ley: pp201602FA4721

ISSN-L: 2542-3029; ISSN: 2610-802X

Universidad Nacional Experimental Francisco de Miranda (UNEFM). Santa Ana de Coro. Venezuela

María-del-Carmen Sagbay-Llivichuzhca; Katina Vanessa Bermeo-Pazmiño; Juan Diego Ochoa-Crespo

Cervera, J. (2002). La transición a las nuevas ISO 9000:2000 y su implantación [The transition to the new ISO 9000:2000 and its implementation ]. España: Díaz de Santos.

Comité para el Desarrollo de la Calidad Total. (2003). Cómo medir la satisfacción del cliente [How to measure customer satisfaction]. España: Asociación Española para la Calidad.

Dutka, A., \& Mazia, A. (1994). Manual de AMA para la satisfacción del cliente [AMA Manual for Customer Satisfaction]. Argentina: NTC Business Books.

Erazo, J. C., \& Narváez, C. I. (2020). La gestión del capital intelectual y su impacto en la efectividad organizacional de la industria de cuero y calzado en la Provincia de Tungurahua - Ecuador [The management of intellectual capital and its impact on the organizational effectiveness of the leather and footwear industry in the Province of Tungurahua - Ecuador]. Revista Espacios, 41(21), 254-271.

Fernández, S. (2013). Gestión de la atención al cliente/cosumidor [Customer/consumer service management]. España: Paraninfo S.A.

García, M., \& Suárez, M. (2013). El método Delphi para la consulta a expertos en la. Cubana de Salud Pública [The Delphi method for consultation with experts in Scientific research]. Revista Cubana de Salud Pública, 39(2), 253-267.

González, H. (2014). Calidad \& Gestion - Consultoría para Empresas [Quality \& Management - Consulting for Companies]. https://n9.cl/xywv5

Guadarrama-Tavira, E., \& Rosales-Estrada, E. (2015). Marketing relacional:valor, satisfacción, lealtad y retención del cliente [Relationship marketing: customer value, satisfaction, loyalty and retention]. Ciencia y Sociedad, 40(2), 307-340.

Guevara-Morocho, P., Narváez-Zurita, C., Erazo-Álvarez, J., \& Machuca-Contreras, M. del C. (2019). Planificación tributaria como herramienta de gestión financiera para el sector industrial de cerámica plana. Caso: Graiman Cía. Ltda. CIENCIAMATRIA, 5(1), 442-473. https://doi.org/10.35381/cm.v5i1.275

Ibáñez, A., \& López, A. (2004). El proceso de la entrevista [The interview process]. México: Limusa. 
Izquierdo, P., \& Ghiggi, I. (2007). Nuevas tecnologias de la información al servicio de la transperencia informativa judicial en el Superior Tribunal de Justicia de la provincia de entre Ríos [New information technologies at the service of judicial information transparency in the Superior]. Dykinson: Madrid.

Kotler, P., \& Armstrong, G. (2007). Marketing: Edición para Latinoamérica [Marketing: Latin America Editiont]. México: Pearson Educación.

Krajewski, L., Ritzman, L., \& Malhotra, M. (2000). Administración de operaciones [Operations Management]. México: Pearson Educación.

Llorens, J. (2005). Gerencia de proyectos de tecnología de información [Information Technology Project Management]. Venezuela: CEC, SA.

López, M. E. (2013). El Buzon de Pacioli [The Pacioli Mailbox]. https://n9.cl/tnb5x

Lucero, L., \& Ferrer, J. (2007). Propuesta preliminar de una escala de satisfacción para clientes mexicanos de supermercados [Preliminary proposal for a satisfaction scale for Mexican supermarket customers]. Pecvnia : Revista de la Facultad de Ciencias Económicas y Empresariales, Universidad de León, O(2010), 5-23. http://dx.doi.org/10.18002/pec.v0i2010.761

Matsumoto-Nishizawa, R. (2014). Desarrollo del Modelo Servqual para la medición de la calidad del servicio en la empresa de publicidad Ayuda Experto [Development of the Servqual Model for measuring the quality of service in the advertising company Expert Help]. PERSPECTIVAS, (34),181-209.

Mendoza-Novillo, P. A., Erazo-Álvarez, J. C., \& Narváez-Zurita, C. I. (2019). Estudio de tiempos y movimientos de producción para Fratello Vegan Restaurant [Study of production times and movements for Fratello Vegan Restaurant]. CIENCIAMATRIA, 5(1), 271-297. https://doi.org/10.35381/cm.v5i1.267

Milind, L., \& Jagdich, S. (1997). El cliente es la clave: cómo lograr una ventaja insuperable mediante la satisfacción del cliente [The customer is the key: how to achieve an unbeatable advantage through customer satisfaction]. España: Díaz de Santos.

Monferrer, D. (2013). Fundamentos de marketing [Marketing Fundamentals]. España: Universitat Jaume I. http://dx.doi.org/10.6035/Sapientia74 
CIENCIAMATRIA

Revista Interdisciplinaria de Humanidades, Educación, Ciencia y Tecnología

Año VII. Vol. VII. N¹2. Enero - Junio. 2021

Hecho el depósito de ley: pp201602FA4721

ISSN-L: 2542-3029; ISSN: 2610-802X

Universidad Nacional Experimental Francisco de Miranda (UNEFM). Santa Ana de Coro. Venezuela

María-del-Carmen Sagbay-Llivichuzhca; Katina Vanessa Bermeo-Pazmiño; Juan Diego Ochoa-Crespo

Mora-Contreras, C. E. (2011). La calidad del sevicio y la satisfacción del consumidor [Service quality and customer satisfaction]. Revista Brasileira de Marketing, 10(2), 146-162.

Paltán-Angumba, A. L., Erazo-Álvarez, J. C., \& Narváez-Zurita, C. I. (2020). Centro de Costeo para prestaciones de los Hospitales de la ciudad de Cuenca -Ecuador [Costing Center for services of the Hospitals of the city of Cuenca -Ecuador]. Revista Arbitrada Interdisciplinaria KOINONIA5(10), 638-670. http://dx.doi.org/10.35381/r.k.v5i10.708

Pujadas, M. P. (2007). Creación y gestión de proyectos editoriales [Creation and management of editorial projects]. Cuenca, Santander, Palma de Mallorca: Universidad de Castilla-La Mancha.

Rivas, \& Ildefonso. (2004). Comportamiento del consumidor decisiones y estrategias de marketing [Consumer behavior marketing decisions and strategies]. Madrid: Esic.

Rodríguez, D., Erazo, J., \& Narváez, C. (2019). Técnicas cuantitativas de investigación de mercados aplicadas al consumo de carne en la generación millennial de la ciudad de Cuenca (Ecuador) [Quantitative techniques of marketing research applied to meat consumption in Cuenca City millennial generation] Revista Espacios, 40(32), 20.

Schiffman, \& Kanuk. (2010). Comportamiento del consumidor [Consumer behavior]. México: Pearson Prentice Hall.

(C2021 por los autores. Este artículo es de acceso abierto y distribuido según los términos y condiciones de la licencia Creative Commons Atribución-NoComercial-Compartirlgual 4.0 Internacional (CC BY-NC-SA 4.0)

(https://creativecommons.org/licenses/by-nc-sa/4.0/). 